\title{
Corrigendum
}

\section{Corrigendum to "Hole Detection for Quantifying Connectivity in Wireless Sensor Networks: A Survey"}

\author{
Pearl Antil and Amita Malik \\ Computer Science and Engineering, DCRUST, Murthal, Sonipat 131039, India \\ Correspondence should be addressed to Amita Malik; amitamalik.cse@dcrustm.org \\ Received 14 June 2016; Accepted 3 August 2016
}

Copyright (C) 2016 P. Antil and A. Malik. This is an open access article distributed under the Creative Commons Attribution License, which permits unrestricted use, distribution, and reproduction in any medium, provided the original work is properly cited.

In the article titled "Hole Detection for Quantifying Connectivity in Wireless Sensor Networks: A Survey" [1] the authors wish to acknowledge the following funding information, which was omitted from it. This work was supported by University Grants Commission (UGC), Government of India, India, by providing the financial assistance for this work under Grant no. 41-626/2012 (SR).

\section{References}

[1] P. Antil and A. Malik, "Hole detection for quantifying connectivity in wireless sensor networks: a survey," Journal of Computer Networks and Communications, vol. 2014, Article ID 969501, 11 pages, 2014. 


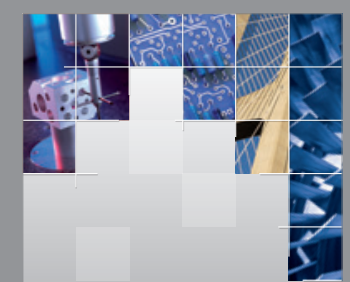

\section{Enfincering}
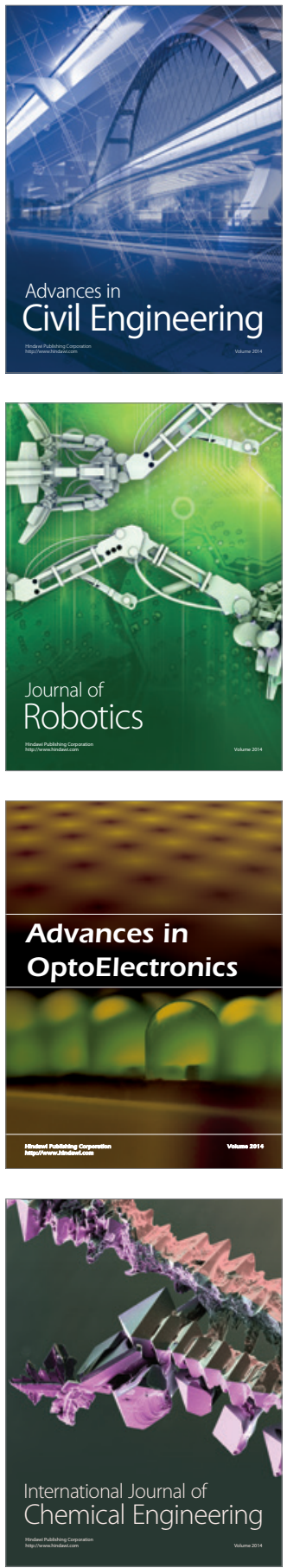

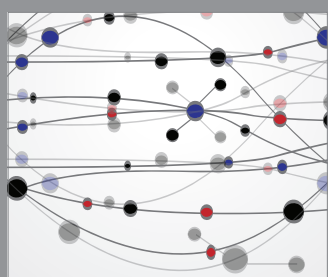

The Scientific World Journal

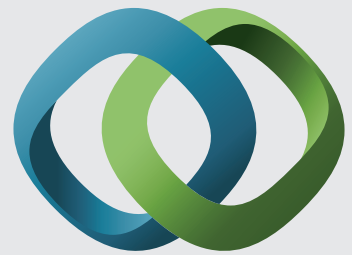

\section{Hindawi}

Submit your manuscripts at

http://www.hindawi.com
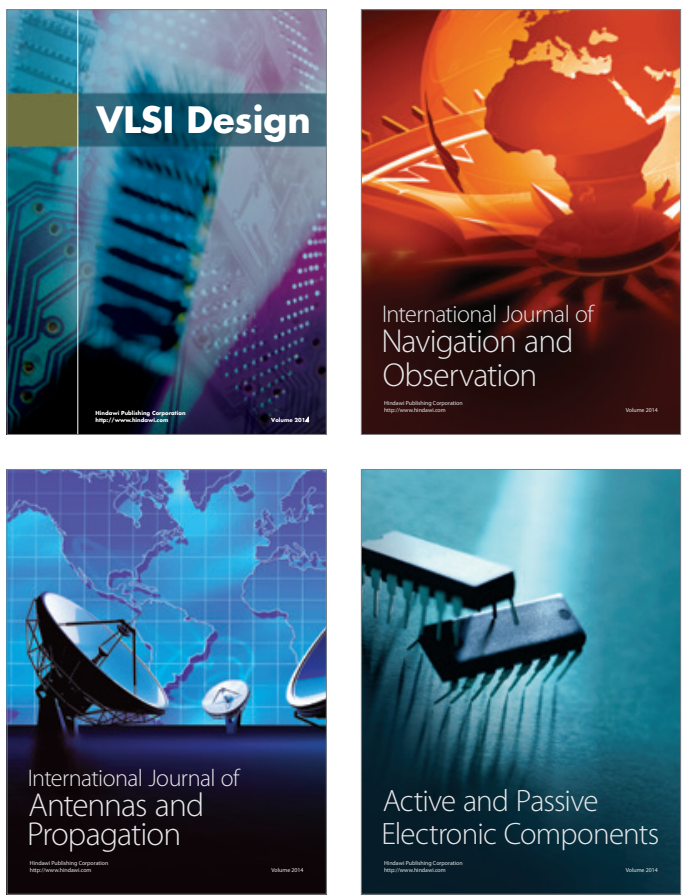
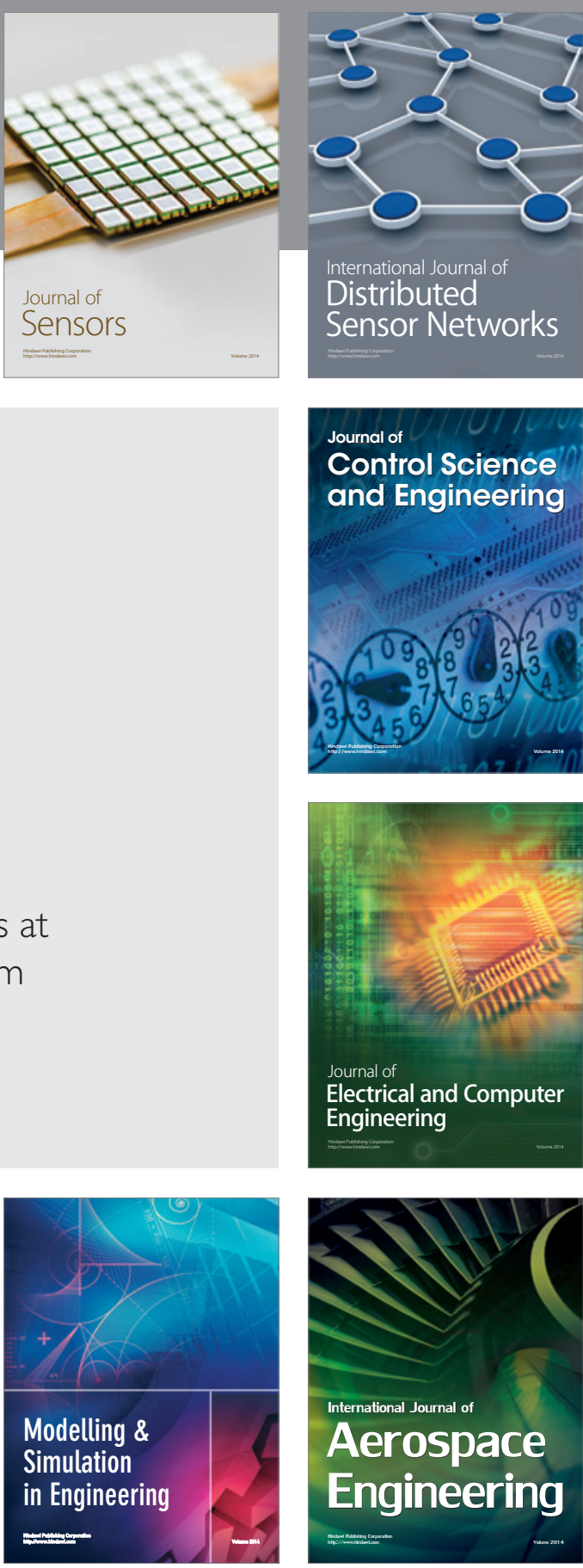

International Journal of

Distributed

Sensor Networks

Journal of

Control Science

and Engineering
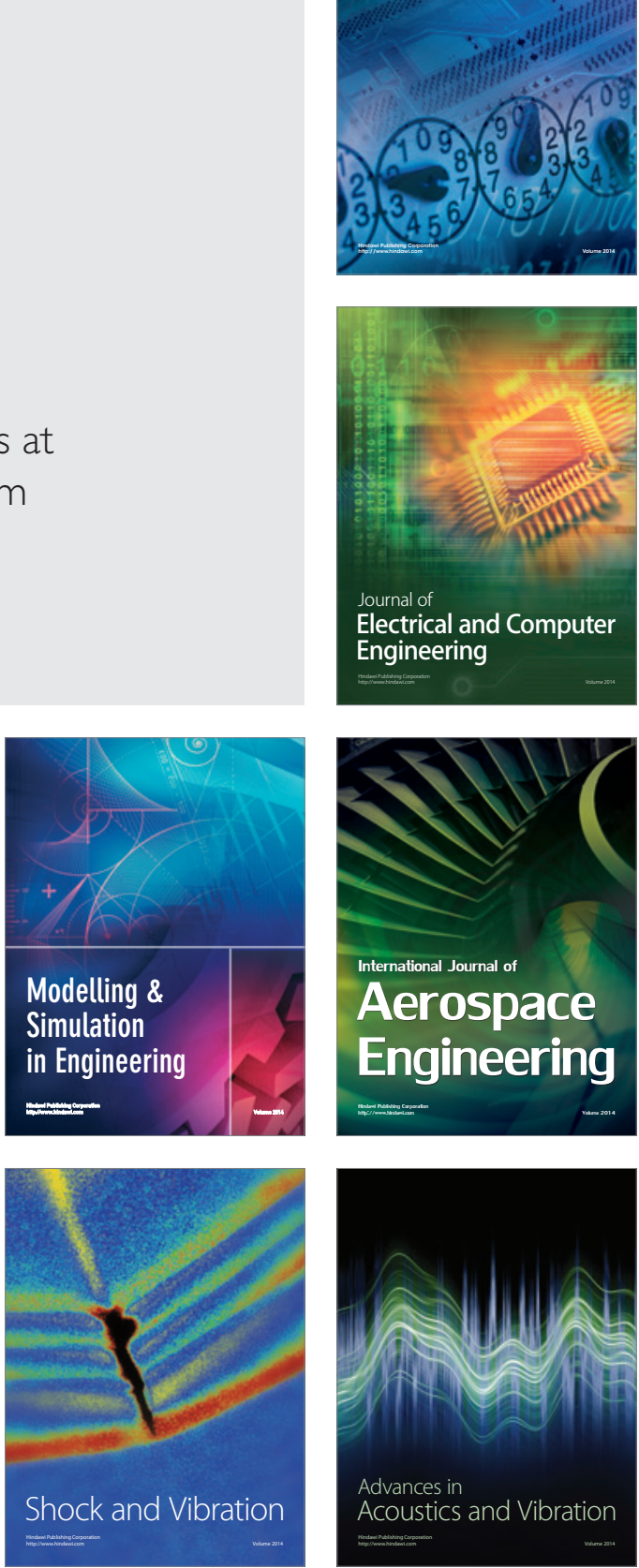